\title{
The effect of ice slurry ingestion on intermittent activity and a run to exhaustion in the heat
}

\author{
Sarah Jackson", Nicola Gerrett \\ From 15th International Conference on Environmental Ergonomics (ICEE XV) \\ Portsmouth, UK. 28 June - 3 July 2015
}

\begin{abstract}
Introduction
Major competitions are often staged in hot environments. However, the body's ability to dissipate heat is compromised during heat stress resulting in a concomitant rise in core temperature $\left(\mathrm{T}_{\mathrm{c}}\right)$, ultimately leading to impaired performance. Precooling methods such as ice vests and cold water immersion are employed before competition, to lower $\mathrm{T}_{\mathrm{c}}$ and increase heat storage before a critical $\mathrm{T}_{\mathrm{c}}$ is reached. However, there are numerous practical limitations meaning pre-existing methods are impractical for use in a field setting. Ice slurry ingestion has been investigated as a more practical precooling method and has enhanced endurance performance [1], however research has yet to determine its effects upon intermittent activity. Therefore the aim of this study was to determine the efficacy of ice slurry ingestion as a precooling method prior to intermittent activity and a run to exhaustion in the heat.
\end{abstract}

\section{Methods}

In a counterbalanced order, ten female footballers (age $20 \pm 1$ years, height $162 \pm 9.5 \mathrm{~cm}$, weight $62.4 \pm 8.5 \mathrm{~kg}$, body fat $23.7 \pm 2.6 \%$, body surface area $1.66 \pm 0.15 \mathrm{~m}^{2}$, $\mathrm{VO}_{2} \max 46.7 \pm 4.6 \mathrm{~mL} \cdot \mathrm{kg}^{-1} \cdot \mathrm{min}^{-1}$ ) either ingested 7.5 g.kg ${ }^{-1}$ ice slurry (IS) or acted as a control (C). After ingestion a 45 minute intermittent shuttle test (walk $4 \mathrm{Km} \cdot \mathrm{h}^{-1}-7$ mins, jog $8 \mathrm{Km} \cdot \mathrm{h}^{-1}-10$ mins, cruise $10 \mathrm{Km} \cdot \mathrm{h}^{-1}-5$ mins, sprint $14 \mathrm{Km} \cdot \mathrm{h}^{-1}-\sim_{3} \mathrm{mins}$ ) was performed, followed by an alternating run to exhaustion (1 min at $65 \% \mathrm{VO}_{2} \max , 1 \mathrm{~min}$ at $95 \%$ until fatigue) in $33^{\circ} \mathrm{C} 59 \% \mathrm{rh} . \mathrm{T}_{\mathrm{c}}$, skin temperature $\left(\mathrm{T}_{\mathrm{sk}}\right)$, heart rate (HR), rating of perceived exertion (RPE), thermal sensation and blood lactate (BLa) were measured during intermittent activity and $T_{c}$ and $H R$ were recorded throughout the run to exhaustion. Gross sweat loss,

\footnotetext{
* Correspondence: S.jackson-14@student.lboro.ac.uk

Institute of Sport and Exercise Science, University of Worcester, UK
}

heat storage and body temperature $\left(\mathrm{T}_{\mathrm{b}}\right)$ was calculated for the entire protocol. A student paired $t$-test was performed upon run time and sweat rate. A $2 \times 2$ repeated measures ANOVA was conducted upon $T_{c}, T_{s k}, T_{b}, H R$, RPE, thermal sensation and BLa. Significance was set at $\mathrm{P} \leq 0.05$.

\section{Results}

Time to exhaustion was significantly longer after ice slurry ingestion when compared to control $(\mathrm{P}=0.0005)$. Prior to exercise ice slurry reduced $\mathrm{T}_{\mathrm{c}}$ by $0.3-1.0{ }^{\circ} \mathrm{C}$ $(P=0.034) . T_{c}$ remained significantly lower on IS compared with $\mathrm{C}$ during the first 30 minutes of intermittent activity $(P=0.05)$. Heat storage was significantly higher $(P=0.003), T_{s k}, T_{b}$ and RPE were significantly lower $(P \leq 0.05)$, and there was a trend for a reduction in thermal sensation throughout intermittent activity in the IS trial $(P=0.064)$. There were no significant differences between conditions in BLa $(\mathrm{P}=0.743), \mathrm{HR}(\mathrm{P}=0.113)$ and sweat rate $(P=0.278)$. At the end of the run to exhaustion $\mathrm{T}_{\mathrm{c}}$ was $0.3{ }^{\circ} \mathrm{C}$ higher on the IS trial $(\mathrm{P}=$ 0.004).

\section{Discussion}

Ice slurry ingestion improved run time by 2 minutes 20 seconds (93 seconds), through reducing $\mathrm{T}_{\mathrm{c}}$ and promoting greater heat storage without any changes in blood lactate accumulation. Previous research indicates this could be due to numerous mechanisms including the reduction of inhibitory afferent feedback to the brain and stimulation of sensory receptors leading to improved perceptual responses.

\section{Conclusion}

Ice slurry ingestion appears to be an effective precooling strategy for use in sports characterised by intermittent activity. Ice slurries are a practical alternative to existing 
methods and could be incorporated into pre-match hydration strategies. Future research should focus on determining the optimal volume and timing of ice slurry ingestion.

Published: 14 September 2015

\section{Reference}

1. Siegel R, Mate J, Brearley MB, Watson G, Nosaka K, Laursen PB: Ice slurry ingestion increases core temperature capacity and running time in the heat. Medicine \& Science in Sports \& Exercise 2010, 42(4):717-725.

doi:10.1186/2046-7648-4-S1-A5

Cite this article as: Jackson and Gerrett: The effect of ice slurry ingestion on intermittent activity and a run to exhaustion in the heat. Extreme Physiology \& Medicine 2015 4(Suppl 1):A5.

Submit your next manuscript to BioMed Central and take full advantage of:

- Convenient online submission

- Thorough peer review

- No space constraints or color figure charges

- Immediate publication on acceptance

- Inclusion in PubMed, CAS, Scopus and Google Scholar

- Research which is freely available for redistribution

Submit your manuscript at www.biomedcentral.com/submit
C Biomed Central 